\section{Finding the ideal}

\section{next role}

Whether you are a dentist, dental hygienist and dental nurse, there will come a time in your career when you need to move into pastures new. However, finding the right position for you can be difficult.

To make sure you get it right, it's important to find a principal or management team who share your values and commitment to quality dentistry. Having access to modern facilities, training opportunities and support are often just as crucial.

At Dental Elite, we have a team of highly experienced dental recruiters who will work with you to find your ideal vacancy. We have extensive knowledge of the market and a wide network of contacts to ensure we are well placed to find your next role. Give us a call if it's time for you to tak the next step in your career.

For more information visit www. dentalelite.co.uk, email recruitment@ dentalelite.co.uk or call 01788545900.

\section{No better time to join this professional academy}

The BACD is a vibrant community of dentists, students, and dental technicians.

A world-leading authority on ethical cosmetic dentistry, the BACD has always been forward thinking when it comes to making every patient feel comfortable and informed. It has comprehensive protocols for treatment planning, indispensable for the challenges ahead.

Patients can feel safe with BACD dentists. Members also have access to unparalleled learning opportunities, including a recently launched online learning portal, to ensure they are upto-date on the latest research and best practice.

To be part of the BACD, and to find out about all its benefits, visit www.bacd.com.

\title{
For patient confidence
}

When you welcome patients back to the practice, you want them to feel safe.

Reinforce your infection control protocols with the Steri-7 Xtra range from Initial Medical, a high-quality cleaning and disinfectant solution for surfaces and hands.

Steri-7 Xtra High Level Surface

Disinfectant Cleaner is available as a

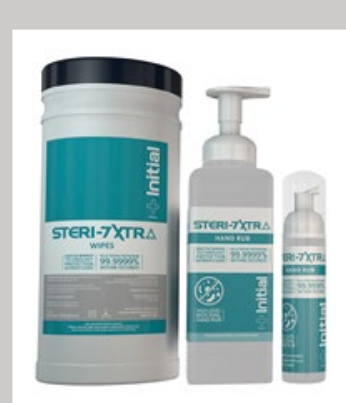
concentrated solution, a ready to use spray, and a surface wipe. The Steri-7 Xtra Personal Care Range includes a hypoallergenic surgical level hand rub and wash, both of which are effective and kind to skin.

Steri-7 Xtra deactivates up to $99.999 \%$ of a broad range of pathogens within seconds of contact and has been test against feline Coronavirus; a surrogate for Coronavirus. Steri-7 Xtra surface sanitisers utilise specially formulated micro emulsion technology that applies an active barrier which can persist and kills for hours afterward. Our supplier's laboratory testing showed the barrier killing microbes (including pathogens) 72 hours after application, so long as the barrier is not wiped away.

With Steri-7 Xtra, your patients can be confident about how protected they are. For further information visit www.initial.co.uk/ medical or call 08708504045 .

\section{Boost your career with cosmetic dentistry}

New figures released by the Oral Health Foundation indicate a surge in the popularity of cosmetic dentistry, pinpointing the under 35 s as having the biggest spend per annum and $53 \%$ having had cosmetic dentistry in the UK. With practices looking to the year ahead in dentistry, could a focus on cosmetic dentistry provide the key to unlocking potential growth, due to this current and now pent up demand? The Academy By Ash offers the ideal three-day smile makeover course for those looking to get started or increase their clinical skills in this area.

In terms of ensuring post COVID-19 safety, delegates may rest assured everything will be taken care of, including delegates being in an AGP-free bubble during the live demonstrations. Using high definition video and audio camera equipment, Ash can teach as he is working on the patient simultaneously - this is truly a unique learning opportunity for dentists that want to excel in restorative $\&$ cosmetic dentistry, with a very thorough understanding of occlusion.

For further information visit www. theacademybyash.co.uk and to book simply go to https://bit.ly/2KLgLNg or call Aditee at Dental Concepts on 07885428887.

\section{New PPE website launched}

As a global leader in the manufacture of PPE, 3M Oral Care has now launched a dedicated website providing more information on the products you need to keep safe.

Solutions available for dental

professionals include:

$\rightarrow 3 \mathrm{M}$ Aura Particulate Health Respirator FFP2, Type IIR 1862+

$\rightarrow 3 \mathrm{M}$ Aura Disposable Health Respirator FFP3, Type IIR, 1863+

$\rightarrow$ Surgical Mask 1826

$\rightarrow$ Splash Resistant Surgical Mask $1820 \mathrm{~S}$ $\rightarrow$ 3M Triple Layer Molded face Mask 2042F

$\rightarrow 3 \mathrm{M}$ Cavilon No Sting Barrier Film

$\rightarrow 3 \mathrm{M}$ Comply SteriGage Integrating Indicator.

Useful information and details of each product can be found on the easy-to-navigate website. For more information, or to request a video call with your local representative, call 08705360036 or visit 3M.co.uk/dental-ppe.
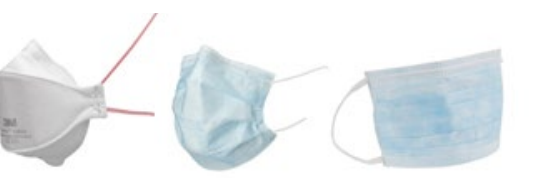